\title{
COMPARAÇÃO ENTRE ÁREAS EM RESTAURAÇÃo E ÁREA DE REFERÊNCIA NO RIO GRANDE DO SUL, BRASIL ${ }^{1}$
}

\author{
Suzane Bevilacqua Marcuzzo ${ }^{2}$, Maristela Machado Araújo ${ }^{3}$, Daniele Guarienti Rorato ${ }^{2}$ Jessica Machado ${ }^{4}$
}

\begin{abstract}
RESUMO - Este estudo teve por objetivo avaliar a evolução da restauração de duas áreas degradadas em unidade de conservação de proteção integral, no bioma Mata Atlântica, no Sul do Brasil. Foram avaliados atributos da composição florística e da estrutura da vegetação, assim como a atividade enzimática do solo (amidase, urease, fosfatase e arilsulfatase), envolvida em processos ecológicos, capazes de caracterizar diferentes áreas em restauração. A vegetação do estrato superior foi amostrada em 18 parcelas de 10 x 20 m em duas áreas recuperadas (A1 e A2) e em 12 parcelas em trecho de floresta utilizada como referência (AR). Nessas parcelas, o componente arbóreo-arbustivo foi medido quanto ao diâmetro, altura e cobertura de copa dos indivíduos, e a regeneração natural foi estudada em subparcelas, através da obtenção do diâmetro do coleto e da altura até $1,0 \mathrm{~m}$. A atividade enzimática foi mensurada por meio da coleta de 10 amostras de solo, nas camadas de 0 a 5 cm e de 5 a $20 \mathrm{~cm}$, em cada área. Os resultados evidenciaram que as áreas em restauração apresentaram menor diversidade $\left(H^{\prime}=2,31\right)$, em comparação com a área de referência $\left(H^{\prime}=3,00\right)$, bem como menores valores de área basal, altura e densidade. Conclui-se que a atividade enzimática é um bom indicador para o desenvolvimento em ambas as áreas restauradas, que comparado à área de referência, ocorrerá a longo prazo, indicando a necessidade de manejo de A1 e A2, por meio da eliminação de gramíneas e espécies arbóreas exóticas, fator determinante para o sucesso da restauração.
\end{abstract}

Palavras-chave: Áreas protegidas; Diversidade; Atividade enzimática.

\section{COMPARISON BETWEEN AREAS IN RESTORATION AND REFERENCE AREA IN RIO GRANDE DO SUL, BRAZIL}

\begin{abstract}
The present study aimed to evaluate the evolution of the restoration of degraded areas, in full protection conservation unit in the Atlantic Forest biome, in southern Brazil. The evaluated attributes were floristic composition and structure of vegetation and soil enzymatic activity (amidase, urease, phosphatase and arylsulfatase), involved in ecological processes, able to characterize different areas in restoration. The vegetation of the upper stratum was sampled in 18 plots of $10 \times 20 \mathrm{~m}$, in two recovered areas (A1 and A2), and in 12 plots in a forest area used as reference (AR). In these plots, the tree-shrub component was measured as for the diameter, height and canopy coverage of individuals and natural regeneration was studied in subplots, through the obtention of the root collar diameter and height. The enzyme activity was measured through the collection of 10 soil samples, in layers ranging from 0 to $5 \mathrm{~cm}$ and 5 to $20 \mathrm{~cm}$ in each area. The results showed that the areas in restoration presented lower diversity $\left(H^{\prime}=2.31\right)$ when compared to the reference area $\left(H^{\prime}=3.00\right)$, as well as lowest basal area, height and density. It is concluded that the enzyme activity
\end{abstract}

\footnotetext{
${ }^{1}$ Recebido em 20.11.2013 aceito para publicação em 08.10.2014.

${ }^{2}$ Universidade Federal de Santa Maria, Programa de Pós-Graduação em Ciências Florestais, Santa Maria, RS - , Brasil. E-mail: <smarcuzzo@gmail.com>e < dannirorato@hotmail.com>.

${ }^{3}$ Universidade Federal de Santa Maria, Departamento de Ciências Florestais, Santa Maria, RS, Brasil.E-mail: <araujo.maristela@gmail.com> . ${ }^{5}$ Universidade Federal de Santa Maria, Programa de Pós-Graduação em Ciência do Solo, Santa Maria, RS - Brasil. E-mail: <jessica.cvm@hotmail.com>.
} 
is a good indicator for the development in both areas restored, which compared to the reference area, will occur in the long term, indicating the need for management of A1 and A2, by eliminating grasses and exotic tree species, the determining factor for the success of the restoration.

Keywords: Protected areas; Diversity; Enzymatic activity.

\section{INTRODUÇÃO}

A restauração ecológica representa estratégia fundamental para resgatar a integridade ecológica dos ecossistemas. Nesse contexto, é necessário conduzir o ecossistema à sua trajetória natural, por meio da autoperpetuação (URBANSKA et al., 1997), levando em consideração a trajetória histórica ou as condições de referência a partir de dados ecológicos e indicadores (RODRIGUES et al., 2009).

Os métodos para restaurar os ecossistemas florestais dependem dos níveis de conservação da floresta e dos solos, do grau de degradação, dos processos ecológicos, da vegetação remanescente e dos resultados de restauração desejados (LAMB et al., 2005).

A Sociedade Internacional para Restauração Ecológica (Society for Ecological Restoration - SER) indica que um ecossistema restaurado deverá apresentar diversidade e estrutura similares às de um ecossistema de referência. Assim, para avaliar o sucesso da restauração, a SER definiu atributos que podem ser agrupados em três categorias: (1) diversidade; (2) estrutura da vegetação; e (3) processos ecológicos (RUIZ-JAEN; AIDE, 2005). Entretanto, a possibilidade de um ecossistema restaurado igualar ou aproximar-se de um ecossistema de referência só pode ser avaliada mediante monitoramento, por meio de indicadores ecológicos (DARONCO et al., 2013). Via de regra, a diversidade é comumente mensurada pela determinação da riqueza e abundância de organismos. Assim como a composição específica de espécies, a estrutura da vegetação é geralmente analisada por sua densidade, biomassa, cobertura da copa ou pelos aspectos fisionômicos da vegetação, sendo essas mensurações úteis para predizer a direção da sucessão de plantas (ENGEL; PARROTTA, 2008).

Processos ecológicos, como a ciclagem de nutrientes, as interações biológicas e, principalmente, as transformações mediadas pela biomassa microbiana têm sua síntese acelerada por enzimas e, consequentemente, proporcionam a quebra da molécula orgânica, facilitando sua mineralização (CARNEIRO et al., 2008). Entre essas enzimas, citam-se: a urease e a amidase; a fosfatase; e a arilsulfatase, envolvida, respectivamente, na disponibilização de nitrogênio, fósforo e enxofre (HAN et al., 2013).

No monitoramento de áreas restauradas, todavia, é possível utilizar diversas variáveis, entre elas a atividade enzimática. A eficiência dessa atividade está relacionada ao mecanismo de sua estabilização no solo, ao papel delas em relação à fertilidade do solo, à nutrição das plantas e à sua contribuição para o ciclo da matéria orgânica. As enzimas se complexam ao húmus por meio de ligações iônicas, covalentes ou de hidrogênio, sendo a maior parte da atividade das enzimas extracelulares no solo e estabilizada na forma de complexos húmicosproteicos (RODRÍGUEZ-LOINAZ et al., 2008).

Este estudo teve por objetivo avaliar a restauração de duas áreas degradadas comparadas a uma área de referência de floresta natural, em unidade de conservação no Rio Grande do Sul, Brasil, buscando-se responder: a) Por meio dos atributos de diversidade, estrutura da vegetação e processos ecológicos, as áreas de estudo se encontram em processo de restauração?; e b) A atividade enzimática é um indicador potencial para avaliar as áreas em restauração deste estudo?

\section{MATERIAL E MÉTODOS}

\subsection{Caracterização da área de estudo}

Este estudo foi realizado na área do Parque Estadual Quarta Colônia (P.E.Q.C.), uma unidade de conservação de proteção integral com território de 1.847,9 ha, cuja coordenada geográfica da sede administrativa é de 29³7’40.80”'S e 53²2’0.38’’O. O Parque está localizado nos Municípios de Agudo e Ibarama, no Rio Grande do Sul, Brasil, mais precisamente na Bacia Hidrográfica do Rio Jacuí (Figura 1).

O solo da região é classificado como Neossolo Litólico e apresenta baixos teores de alumínio trocável, contendo $12 \mathrm{~g} \mathrm{~kg}^{-1}$ de carbono orgânico (PEDRON; DALMOLIN, 2011). Especificamente na área de estudo, 


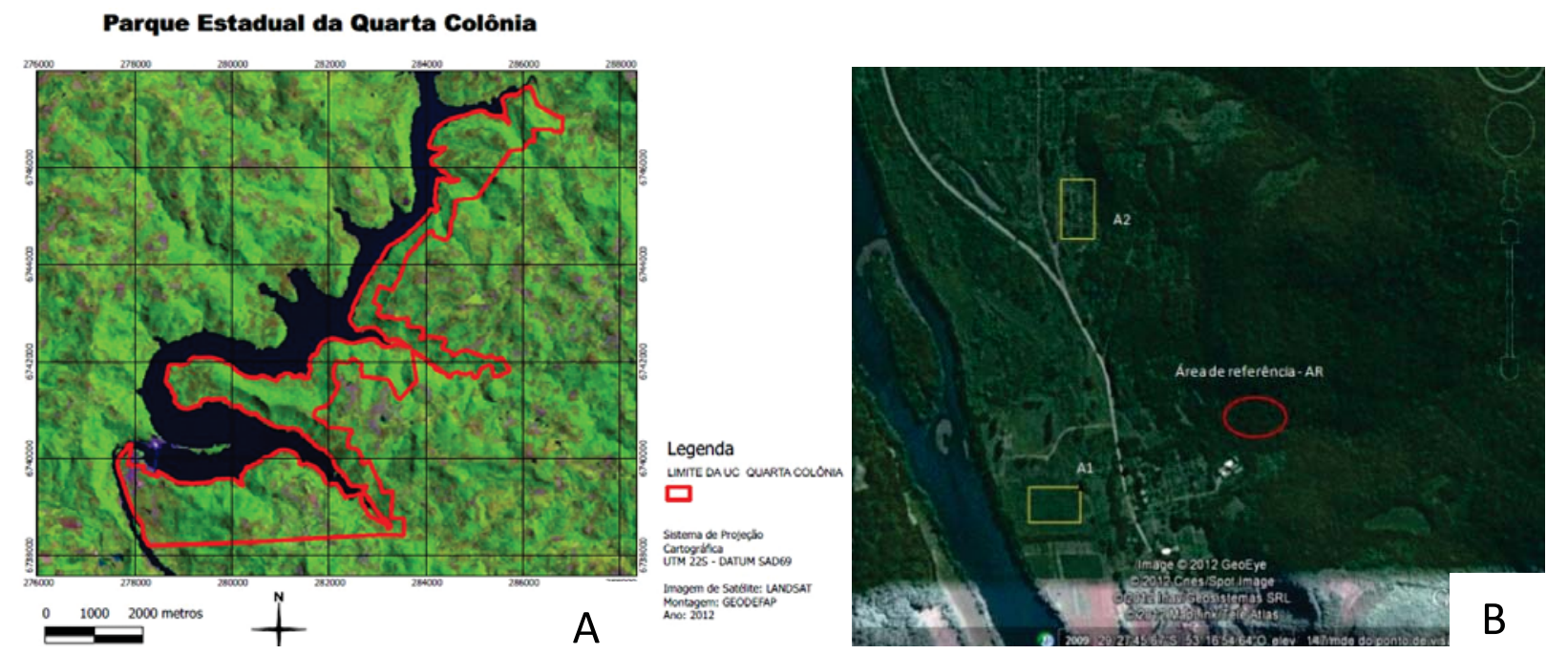

Figura 1 - Limites do Parque Estadual Quarta Colônia, Agudo, RS, Brasil (A); áreas de estudo em processo de restauração e área de referência (B).

Figure 1 - Limits of the State Park Fourth Colony (Parque Estadual Quarta Colônia), Agudo, RS, Brazil (A); study areas in restoration process and reference area $(B)$.

Marcuzzo (2012) constatou em análise de solo ph em torno de 6,3, além de altos teores de Ca (25 $\left.\mathrm{cmolc} \mathrm{kg-}^{-1}\right)$ e $\mathrm{Mg}$ (6 cmolc $\left.\mathrm{kg}^{-1}\right)$ e baixo a médio teor de $\mathrm{P}(0,6 \mathrm{cmolc}$ $\left.\mathrm{kg}^{-1}\right)$.

Segundo a classificação de Köppen, o clima regional é subtropical, pertencente à variedade específica Cfa (NIMER, 1990). A vegetação é inerente à região fitogeográfica de Floresta Estacional Subtropical (SCHUMACHER et al., 2011).

O Parque Estadual Quarta Colônia, pode ser caracterizado por apresentar encostas florestadas, além de áreas em processo de restauração, as quais foram degradadas durante a construção da barragem da Usina Hidrelétrica de Dona Francisca.

Tendo em vista a obrigatoriedade de o empreendedor recuperar as áreas degradadas, nesse estudo selecionaram-se duas áreas (A1 e A2), ambas com sete anos de plantio, para caracterizar a restauração e comparála a uma área de floresta nativa, usada como referência (AR). Tais ambientes apresentam as seguintes características:

1) Área 1 (A1): área de 2,21 ha remanescente de antigos cultivos sucessivos de fumo, distante cerca de $560 \mathrm{~m}$ da área de referência. No plantio foram utilizadas 12 espécies, entre elas espécies pioneiras (Schinnus terebinhtifolius Raddi, Inga vera Willd., Parapiptadenia rigida (Benth.) Brenan, Ateleia glazioviana Baill., Psidium cattleyanum L.) e secundárias iniciais (Prunus myrtifolia (L.) Urb., Vitex megapotamica (Spreng.) Moldenke, Cedrela fissilis Vell., Ficus luschnathiana (Miq.) Miq., Luehea divaricata Mart., Peltophorum dubium Sprengel e Ocotea puberula (Rich.)). Após a subsolagem, foram abertas covas nas linhas de sulcos, e as mudas foram plantadas com espaçamento de 2,5 x 2,5 m, totalizando 5.000 mudas, que receberam tratos culturais pelo período de 24 meses.

2) Área 2 (A2): área de 2,27 ha, vila de operários desmobilizada desde 2001. Encontra-se a 615 m da área de referência e a 78 m de distância de uma área de encosta com floresta secundária em estágio médio de sucessão. O solo apresentava-se compactado e com presença de resíduos de construção (75\% de matacões com fração $>200$ mm) (PEDRON et al., 2010), provenientes da demolição de antigas benfeitorias. Nessa área, foram plantadas 24 espécies, entre pioneiras (Parapiptadenia rigida, Psidium cattleyanum, Schinus terebinthifolius, Enterolobium contortisiliquum (Vell.) Morong, Calliandra brevipes (Spreng.) J. F. Macbr), secundárias iniciais (Allophylus edulis (A.St.-Hil., Cambess. \& A. Juss.) Radlk., Strychnos brasiliensis (Spreng.) Mart., Cordia americana (L.) Gottshling \& J.E.Mill., Luehea

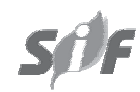

Revista Árvore, Viçosa-MG, v.38, n.6, p.961-972, 2014 
divaricata, Peltophorum dubium, Cedrela fissilis Vell., Schizolobium parahyba, Cabralea canjerana (Vell.) Mart, Handroanthus heptaphyllus, Handroanthus chrysotrichus, Jacaranda micrantha, Eugenia uniflora, Campomanesia xanthocarpa O. Berg, Vitex megapotamica, Cordia trichotoma (Vell.) Arrab. ex Stend.) e tardias (Ficus luschnathiana, Eugenia involucrata DC, Annona rugulosa (Schltdl.) H. Rainer, Myrcianthes pungens (O. Berg.) D. Legrand). O espaçamento utilizado foi de 4 x 4 m, e não houve preparo do solo nem tratos culturais, sendo o plantio realizado em covas. As mudas utilizadas em A1 e A2 foram produzidas no viveiro florestal da Companhia Estadual de Energia Elétrica (CEEE), semeadas em sacos de polietileno de $1 \mathrm{~L}$.

3) Área de referência (AR): trecho de encosta de Floresta Estacional Subtropical secundária, próximo de 556 m da A1 e 615 m da A2. A área está há 20 anos, aproximadamente, sem intervenções antrópicas, e antes disso havia pequenas propriedades nos trechos menos íngremes, o que reflete, atualmente, num mosaico de diferentes estádios sucessionais (MARCUZZO et al., 2013).

\subsection{Amostragem e análise da vegetação e do solo}

A vegetação nas três áreas foi avaliada em duas classes (I e II). Nas duas áreas em restauração (A1 e A2), consideraram-se na classe I os indivíduos plantados estabelecidos, independentemente do diâmetro, e aqueles com circunferência à altura do peito $(\mathrm{CAP}) \geq 15$ cm; e na área de referência (AR) apenas os indivíduos com CAP $\geq 15 \mathrm{~cm}$. Na classe II, foi contemplada a regeneração natural, caracterizada pelos indivíduos com altura $\geq 30 \mathrm{~cm}$ e CAP $<15 \mathrm{~cm}$.

Visando entender o desenvolvimento do componente arbóreo-arbustivo nas áreas recuperadas (A1 e A2), realizou-se inventário em parcelas de 200 $\mathrm{m}^{2}(10 \times 20 \mathrm{~m})$. As parcelas foram distribuídas a cada $10 \mathrm{~m}$, dentro de seis faixas, distantes $20 \mathrm{~m}$ entre si. Foram utilizadas 18 parcelas, totalizando $3.600 \mathrm{~m}^{2}$ (0,36 ha), em cada área (A1 e A2).

Em ambas as áreas, a regeneração natural foi mensurada em parcelas de 2 × $2 \mathrm{~m}$, localizadas no canto esquerdo das parcelas de 10 x 20 m. Em cada parcela, foi realizada a identificação de todos os indivíduos arbóreos e arbustivos plantados, bem como a medição da circunferência à altura do peito (CAP), da cobertura de copa e da altura total. Os indivíduos arbóreos e arbustivos da regeneração de até 1,0 m de altura foram medidos com fita métrica e o diâmetro do coleto, mensurado com paquímetro.

Os dados da floresta nativa, selecionada como área de referência (AR), foram obtidos em 12 parcelas de mesma dimensão e distribuição, com faixas distantes 100 m uma da outra. Foi realizada a identificação, a medição da circunferência à altura do peito (CAP) e da altura total dos indivíduos arbóreos e arbustivos $(\mathrm{CAP} \geq 15 \mathrm{~cm})$. A regeneração natural foi medida em parcelas com raio de $1,78 \mathrm{~m}\left(10 \mathrm{~m}^{2}\right)$, conforme proposto por Finger (1992), mensurando os indivíduos com altura $\geq 30 \mathrm{~cm}$ e CAP $<15 \mathrm{~cm}$.

As plantas foram identificadas e conduzidas ao Herbário do Departamento de Ciências Florestais da Universidade Federal de Santa Maria (UFSM). E as espécies foram identificadas segundo as famílias determinadas pelo sistema Angiosperm Phylogeny Group III (APGIII, 2009).

Os indivíduos arbóreos e arbustivos plantados (A1 e A2) e aqueles com circunferência a 1,3 m da superfície do solo (CAP) $\geq 15 \mathrm{~cm}$, na área de referência, foram analisados em relação à estrutura horizontal, com base nos parâmetros fitossociológicos (densidade, dominância, frequência e valor de importância), conforme descrito em Felfili et al. (2011).

A projeção da copa, em A1 e A2, foi calculada por $\mathrm{C}=\Sigma_{1}^{n}=C_{i} / \mathrm{A} .100$, em que $\mathrm{C}=$ percentual de cobertura (\%); Ci = área da projeção da copa do indivíduo i $\left(\pi .(D i)^{2} / 4\right) ; \mathrm{Di}=$ diâmetro médio $(\mathrm{m})$ da copa do indivíduo i; $\mathrm{n}$ = número de indivíduos medidos na área $\mathrm{A}$; e $\mathrm{A}$ = área $\left(\mathrm{m}^{2}\right)$ útil da parcela (MELO; DURIGAN, 2007). A diversidade florística foi estimada pelo índice de diversidade de Shannon ( $\left.\mathrm{H}^{\prime}\right)$ e a equabilidade, pelo coeficiente de Pielou (J') (BROWER; ZAR, 1984).

Nas três áreas, os dados da atividade enzimática no solo foram obtidos por meio da coleta de 10 amostras de solo das camadas de 0 a $5 \mathrm{~cm}$ e de 5 a $20 \mathrm{~cm}$, em cada área. As amostras foram analisadas após a coleta, peneiradas com malha de 2 mm de diâmetro em laboratório, e as atividades de amidase, urease, fosfatase e arilsulfatase foram determinadas por metodologias comumente utilizadas para determinação de tais enzimas (TABATABAI, 1994), no Laboratório de Microbiologia do Departamento de Ciência do Solo da UFSM. 
As atividades enzimáticas no solo de amidase, urease, fosfatase e arilsulfatase foram, inicialmente, analisadas quanto às suas pressuposições e, posteriormente, realizou-se análise de variância e comparação das médias pelo teste de Tukey $(\mathrm{p} \geq 0,05)$.

A ordenação da vegetação (matriz principal) em relação às variáveis ambientais (matriz secundária) foi realizada através da análise de correspondência canônica (CCA), em cada uma das três áreas (A1, A2, AR) (FELFILI et al., 2011). Para ordenação do componente arbóreo, foram utilizadas matrizes com dados da área basal, em virtude de que, das três áreas, duas os indivíduos foram plantados. As linhas e colunas da matriz representaram, respectivamente, as parcelas e espécies presentes.

Na análise da regeneração, as matrizes foram elaboradas com os dados de abundância das espécies. A matriz ambiental englobou as informações sobre a atividade das enzimas amidase, urease, fosfatase e arilsulfatase. Os dados referentes às espécies e ao ambiente foram adequados à análise, por meio da transformação por logaritmo neperiano, sendo, posteriormente, utilizado o programa PC-ORD for Windows, versão 5.0 (McCUNE; MEFFORD, 2006). A análise de correspondência canônica, diagramação e significância das correlações entre as matrizes foram feitas através do teste de permutação de Monte Carlo. Na CCA, nas três áreas (A1, A2 e AR) e nas duas classes de tamanho (componente arbóreo e sub-bosque) foram selecionados os eixos que permitiram a melhor explicação dos dados.

\section{RESULTADOS}

\subsection{Estrutura da vegetação e diversidade}

Os parâmetros relacionados à estrutura e diversidade apresentam valores crescentes de A 1 a AR, observando-se diferença expressivamente menor entre as áreas em restauração quando comparadas com a floresta natural. Destaca-se, por exemplo, que as duas áreas em processo de restauração (A1 e A2) apresentaram área basal similar, respectivamente, 3,701 e 4,269 $\mathrm{m}^{2} \mathrm{ha}^{-1}$. Entretanto, esses valores foram menores quando comparados com a área de referência (AR), que apresentou área basal de 28,64 $\mathrm{m}^{2} \mathrm{ha}^{-1}$. Entretanto, observou-se maior variação entre as alturas médias (Tabela 1).

Houve o predomínio de espécies zoocóricas em relação às anemocóricas em todas as áreas estudadas, tanto no componente arbóreo-arbustivo (classe I) quanto na regeneração natural (classe II), enquanto a proporção de pioneira em relação às não pioneiras foi menor nas áreas em restauração do que na área de referência.

Considerando a estrutura horizontal da floresta na classe I, as cinco espécies predominantes foram diferentes nas três áreas, constatando-se a soma do valor de importância de 68,40\% na A1, 47,27 na A2 e 34,08 na AR (Tabela 2).

Tabela 1 - Estrutura e diversidade em Floresta Estacional Subtropical de área natural de referência (AR) e em áreas em processo de restauração (A1 e A2), no Parque Estadual Quarta Colônia, Agudo, RS.

Table 1 - Structure and diversity in Subtropical seasonal forest of natural area of reference (AR) and in areas in restoration process (A1 and A2) in State Park Fourth Colony (Parque Estadual Quarta Colônia), Agudo, RS.

\begin{tabular}{|c|c|c|c|c|c|c|}
\hline & \multicolumn{3}{|c|}{ COMPONENTE ARBÓREO } & \multicolumn{3}{|c|}{ REGENERAÇÃO NATURAL } \\
\hline & A1 & A2 & $\mathrm{AR}$ & A1 & A2 & AR \\
\hline Idade (anos) & 7 & 7 & \pm 20 & - & - & - \\
\hline Espaçamento de plantio (m) & $2 \times 2$ & $4 \times 4$ & - & - & - & - \\
\hline Altura média (m) & 3,15 & 4,3 & 9,3 & 0,44 & 1,0 & 2,8 \\
\hline Área basal $\left(\mathrm{m}^{2} / \mathrm{ha}^{-1}\right)$ & 4,128 & 4,269 & 27,131 & - & - & - \\
\hline Densidade (ind.ha ${ }^{-1}$ ) & 1.741 & 297 & 3.408 & 23.333 & 11.388 & 15.909 \\
\hline Cobertura de copa (\%) & 109,3 & 35,7 & - & - & - & - \\
\hline Riqueza & 19 & 29 & 49 & 21 & 16 & 42 \\
\hline Diversidade (H’) & 2,31 & 2,86 & 3,00 & 2,23 & 2,29 & 2,60 \\
\hline Equabilidade (J’) & 0,78 & 0,85 & 0,78 & 0,73 & 0,82 & 0,69 \\
\hline Plantas zoocóricas (\%) & 58 & 70 & 75,2 & 62 & 56,25 & 79,5 \\
\hline Plantas anemocóricas (\%) & 42 & 30 & 24,8 & 38 & 43,75 & 20,5 \\
\hline Grupo sucessional (\% P:NP) & $47: 53$ & $48: 52$ & 18:82 & $52: 48$ & $44: 56$ & $12: 88$ \\
\hline Espécies exóticas (\%) & 26,3 & 17.2 & 0 & 28.5 & 31.2 & 0 \\
\hline
\end{tabular}

Em que: $(\% \mathrm{P}: \mathrm{NP})=$ porcentual de espécies pioneiras $(\mathrm{P})$ em relação às não pioneiras $(\mathrm{NP})$. Where in: $(\% P: N P)=$ percentage of pioneer species $(P)$ in relation to non-pioneer $(N P)$. 
Tabela 2 - Estrutura horizontal das cinco espécies mais bem hierarquizadas do estrato arbóreo em Floresta Estacional Subtropical, representada por área natural de referência (AR) e áreas em processo de restauração (A1 e A2), no Parque Estadual Quarta Colônia, RS, Brasil

Table 2 --Horizontal structure of the five species that are better prioritised of the tree layer in Subtropical seasonal forest, represented by natural area of reference (AR) and areas in restoration process (A1 and A2) in State Park Fourth Colony (Parque Estadual Quarta Colônia), RS, Brazil

\begin{tabular}{|c|c|c|c|c|c|c|c|c|c|c|c|c|}
\hline \multirow[t]{2}{*}{ Espécie e (GS) } & \multicolumn{4}{|c|}{ A1 - plantada } & \multicolumn{4}{|c|}{ A2 - plantada } & \multicolumn{4}{|c|}{ AR - referência } \\
\hline & $\mathrm{DA}$ & FA & DoA & VI\% & DA & FA & DoA & VI\% & $\mathrm{DA}$ & FA & DoA & VI\% \\
\hline $\begin{array}{l}\text { Allophylus edulis } \\
\text { (A.St.-Hil., Cambess. } \\
\text { \& A. Juss.) Radlk. (SI) }\end{array}$ & - & - & & - & - & - & & - & 121 & 58.33 & 1.81 & 5.93 \\
\hline $\begin{array}{l}\text { Ateleia glazioviana } \\
\text { Baill. (P) }\end{array}$ & 261.11 & 83.33 & 1.29 & 19.81 & - & - & & - & - & - & & - \\
\hline $\begin{array}{l}\text { Ficus luschnatiana } \\
\text { (Miq.) Miq. (ST) }\end{array}$ & - & - & & - & 2.78 & 5.56 & 0.71 & 6.4 & - & - & & - \\
\hline $\begin{array}{l}\text { Cordia americana (L.) } \\
\text { Gottshling \& J.E.Mill. (SI) }\end{array}$ & - & - & & - & - & - & & - & 92 & 66.66 & 1.9 & 5.85 \\
\hline $\begin{array}{l}\text { Cupania vernalis } \\
\text { Cambess. (SI) }\end{array}$ & - & - & & - & - & - & & - & 171 & 75 & 1.67 & 7.18 \\
\hline $\begin{array}{l}\text { Enterolobium contortisiliquum } \\
\text { (Vell.) Morong (P) }\end{array}$ & $n$ & - & & - & 38.89 & 50.00 & 1.04 & 17.16 & - & - & & - \\
\hline $\begin{array}{l}\text { Gymnanthes concolor } \\
\text { Spreng. (SI) }\end{array}$ & - & - & & - & - & - & & - & 208 & 66.67 & 0.86 & 6.76 \\
\hline Inga vera Willd. (P) & 152.78 & 66.67 & 0.97 & 14.26 & - & - & & - & - & - & & - \\
\hline $\begin{array}{l}\text { Luehea divaricata } \\
\text { Mart. (SI) }\end{array}$ & 211.11 & 61.11 & 0.07 & 7.21 & - & - & & - & - & - & & - \\
\hline $\begin{array}{l}\text { Nectandra megapotamica } \\
\text { (Spreng) Mez (ST) }\end{array}$ & - & - & & - & - & - & & - & 125 & 83.3 & 3.95 & 9.11 \\
\hline $\begin{array}{l}\text { Parapiptadenia rigida } \\
\text { (Benth.) Brenan (P) }\end{array}$ & & & & & 55.56 & 38.89 & 0.08 & 10.49 & - & - & & - \\
\hline Pinus elliottii Engelm (P) & & & & & 36.11 & 22.22 & 0.23 & 7.96 & - & - & & - \\
\hline $\begin{array}{l}\text { Psidium cattleyanum } \\
\text { L. (P) }\end{array}$ & 408.33 & 100.00 & 0.32 & 14.76 & - & - & & - & - & - & & - \\
\hline $\begin{array}{l}\text { Schinus terebinthifolius } \\
\text { Raddi (P) }\end{array}$ & 233.33 & 72.22 & 0.55 & 12.33 & - & - & & - & - & - & & - \\
\hline $\begin{array}{l}\text { Syzygium cumini (L.) } \\
\text { Skeels (P) }\end{array}$ & - & - & & - & 8.33 & 11.11 & 0.42 & 5.27 & - & - & & - \\
\hline Total (5 espécies) & 1267 & 383 & 3.2 & 68.4 & 142 & 128 & 2.48 & 47.3 & 717 & 350 & 10.25 & 34 \\
\hline Total (restante das espécies) & 475 & 417 & 0.5 & 31.6 & 155.2 & 227.6 & 1.79 & 52.7 & 999 & 950 & 18.4 & 66 \\
\hline Total geral & 1742 & 800 & 3.7 & 100 & 297 & 356 & 4.27 & 100 & 1706 & 1309 & 28.6 & 100 \\
\hline
\end{tabular}

DA: densidade absoluta; FA: frequência absoluta; DoA: dominância absoluta; VI\%: percentual de valor de importância; (GS): grupo sucessional; (P): pioneira; (SI): secundária inicial; e (ST): secundária tardia.

DA: absolute density; FA: absolute frequency; DoA: absolute dominance; VI\%: importance value percentage; (GS): successional group; $(P)$ : pioneer; (SI): early secondary; and (ST): late successional..

Na classe II (regeneração natural), constata-se elevada riqueza na AR (42 espécies), em relação A1 (21) e A2 (16), porém com valor de densidade intermediária em AR (15.909 indivíduos) do que na A1 (23.333) e A2 (11.388). Em ambas as áreas em restauração, destaca-se a presença de Psidium guajava, espécie de característica pioneira e zoocórica. Observou-se nas áreas em recuperação grande representatividade de espécies exóticas invasoras (Tabela 3).

\subsection{Processos ecológicos - Atividade enzimática no solo}

As enzimas de solo, amidase, urease, fosfatase ácida e arilsulfatase, na profundidade de 0-5 cm da área de referência na floresta (AR), apresentaram, respectivamente, os valores de 764 e $126 \mathrm{mg} \mathrm{NH}^{4+} \mathrm{Kg}^{-1} \mathrm{~h}^{-1}$; e 564 e $154 \mu$ g $\rho$-nitrofenol $\mathrm{g}^{-1} \mathrm{~h}^{-1}$, estatisticamente superiores, pelo teste de Tukey $(p<0,05)$, aos das duas áreas em restauração 
Tabela 3 - Densidade e frequência absoluta das cinco espécies mais bem hierarquizadas na regeneração de Floresta Estacional Subtropical de área natural de referência (AR) e áreas em processo de restauração (A1 e A2), no Parque Estadual Quarta Colônia, RS, Brasil.

Table 3 -Density and absolute frequency of the five species that are better prioritised in the regeneration of Subtropical seasonal forest of natural area of reference (AR) and areas in restoration process (A1 and A2) in State Park Fourth Colony (Parque Estadual Quarta Colônia), RS, Brazil.

\begin{tabular}{|c|c|c|c|c|c|c|}
\hline \multirow[t]{2}{*}{ Espécie e (GS) } & \multicolumn{2}{|c|}{ A1 - plantada } & \multicolumn{2}{|c|}{ A2 - plantada } & \multicolumn{2}{|c|}{ AR - natural } \\
\hline & DA & FA & DA & FA & DA & FA \\
\hline $\begin{array}{l}\text { Allophylus edulis (A.St.-Hil., et al.) Hieron. } \\
\text { Ex Niederl. (SI) }\end{array}$ & & & & & 958,3 & 58.33 \\
\hline Caliandra brevipes (Spreng.) J. F. Macbr. (P) & & & 1805,56 & 33.33 & & \\
\hline Cordia trichotoma (Vell.) Arráb. ex Stend. (SI) & - & & 833,33 & 5.56 & & \\
\hline Cupania vernalis Cambess. (SI) & & & & & 2750 & 83.33 \\
\hline Gymnanthes concolor (Spreng.) Müll. Arg. (SI) & & & & & 6000 & 83.33 \\
\hline Hovenia dulcis Thunb. (P) & 2916,7 & 16,67 & & & & \\
\hline Inga vera Willd. (P) & 1805,6 & 27,78 & & & & \\
\hline Ocotea puberula (A.Rich.) Ness (P) & 1527,8 & 33,33 & & & & \\
\hline Pinus elliottii Engelm. (P) & & & 694,44 & 11.11 & & \\
\hline Psidium guajava L. (P) & 1944,4 & 38,89 & 3333,3 & 44.44 & & \\
\hline Schinnus terebinthifolius Raddi (P) & 8750 & 61,11 & & & & \\
\hline Syzygium cumini (L.) Skeels (P) & & & 1388,89 & 11.11 & & \\
\hline Trichilia clausseni C.DC. (SI) & & & & & 1166,7 & 58.33 \\
\hline Trichilia elegans A. Juss. (ST) & & & & & 1083,3 & 75 \\
\hline Total (13 espécies) & 16944,5 & 178 & 8055,52 & 106 & 12558,3 & 358 \\
\hline Total (restante das espécies) & 6388,8 & 177,55 & 3333,38 & 88.44 & 3350,7 & 750.3 \\
\hline Total geral & 23333,3 & 355,55 & 11388,9 & 194.44 & 15909 & 1108.3 \\
\hline
\end{tabular}

DA: densidade absoluta; FA: frequência absoluta; (GS): grupo sucessional; (P): pioneira; (SI): secundária inicial; e (ST): secundária tardia. DA: absolute density; FA: absolute frequency; (GS): successional group; (P): pioneer; (SI): early secondary; and (ST): late successional.

(A1 e A2). Entretanto, na profundidade de 5-20 $\mathrm{cm}$ a enzima amidase discriminou melhor a qualidade do solo, sendo observados valores de $542 \mathrm{mg}$ $\mathrm{NH}^{4+} \mathrm{Kg}^{-1} \mathrm{~h}^{-1}$ na área de floresta, enquanto para as demais enzimas essa área apresentou tendência similar.
Os resultados apontaram a presença de atividade enzimática em todas as áreas, embora com diferença expressiva entre as áreas em restauração e área de referência, que permitiu verificar por meio da CCA a relação existente entre as espécies e a atividade bioquímica dos solos (Tabela 4).

Tabela 4 - Resumo da estatística dos eixos de distribuição das parcelas e espécies com relação à atividade das enzimas (variáveis ambientais) de cada área, quanto ao estrato arbóreo e à regeneração.

Table 4-Statistical summary of the axes of distribution of plots and species regarding the activity of enzymes (environmental variables) for each area as for the tree layer and regeneration.

\begin{tabular}{|c|c|c|c|c|c|c|c|c|c|c|c|c|}
\hline & \multicolumn{6}{|c|}{ COMPONENTE ARBÓREO } & \multicolumn{6}{|c|}{ REGENERAÇÃO NATURAL } \\
\hline & \multicolumn{2}{|c|}{ A 1} & \multicolumn{2}{|c|}{ A2 } & \multicolumn{2}{|c|}{ AR } & \multicolumn{2}{|r|}{ A1 } & \multicolumn{2}{|c|}{$\mathrm{A} 2$} & \multicolumn{2}{|c|}{ AR } \\
\hline & \multicolumn{12}{|c|}{ Correlações } \\
\hline & Eixo 1 & Eixo 2 & Eixo 1 & Eixo 2 & Eixo 2 & Eixo 3 & Eixo 1 & Eixo 2 & Eixo 1 & 1 Eixo 2 & Eixo 2 & Eixo 3 \\
\hline Autovalores & 0.382 & 0.255 & 0.876 & 0.667 & 0.436 & 0.325 & 0.781 & 0.53 & 0.491 & 0.322 & 0.320 & 0.201 \\
\hline \% da variância & 39.1 & 26.1 & 32.9 & 25.0 & 18.2 & 13.6 & 24.9 & 16.9 & 31.0 & 20.4 & 23.0 & 14.5 \\
\hline $\begin{array}{l}\text { \% da variância } \\
\text { acumulada }\end{array}$ & 65.2 & 57.9 & 31.8 & 41.8 & 51.4 & 37.5 & & & & & & \\
\hline $\begin{array}{l}\text { Teste de Monte } \\
\text { Carlo- autovalores }\end{array}$ & $\mathrm{p}=$ & 0.003 & $\mathrm{p}=0$. & 0010 & $\mathrm{p}=$ & 0.001 & $\mathrm{p}=$ & 0.002 & $\mathrm{p}=0$ & 0.001 & & 0.001 \\
\hline $\begin{array}{l}\text { Teste de Monte } \\
\text { Carlo- correlações }\end{array}$ & $\mathrm{p}=$ & 0.002 & $\mathrm{p}=0$ & .002 & $\mathrm{p}=$ & 0.006 & $\mathrm{p}=$ & 0.004 & $\mathrm{p}=0$ & 0.004 & $\mathrm{p}=$ & 0.008 \\
\hline
\end{tabular}


O teste de permutação de Monte Carlo, em todas as áreas, revelou alta correlação entre a vegetação e as variáveis ambientais. $\mathrm{Na} \mathrm{A} 1$, as enzimas mais correlacionadas com o primeiro eixo de ordenação foram amidase e arilsulfatase na camada de $0-5 \mathrm{~cm}$ de solo, provavelmente influenciadas pela vegetação na Classe I. Na A2, o segundo eixo de ordenação apresentou melhor correlação com a amidase na profundidade de $0-5 \mathrm{~cm}$ e com a fosfatase em ambas as profundidades (0-5 e 5-20 cm). A área de referência (AR) apresentou amidase, urease, fosfatase e arilsulfatase na camada de 5-20 cm, mais correlacionadas com o terceiro eixo.

Ainda na A1, as enzimas mais correlacionadas com o segundo eixo de ordenação foram a urease (0-5 e 5-20 cm) e a arilsulfatase (5-20 cm). Já na A2 as enzimas mais correlacionadas com o terceiro eixo foram amidase (0-5 e 5-20 cm), urease $(0-5$ e 5-20 cm) e fosfatase $(0-$ $5 \mathrm{~cm})$. E na área de referência (AR) a enzima mais correlacionada com o primeiro eixo foi a arilsulfatase (0-5 cm).

\section{DISCUSSÃO}

Os resultados das análises efetuadas quanto à estrutura de vegetação, diversidade e atividade enzimática indicaram a expressiva diferença entre as áreas em processo de restauração e a área de referência. Isso é possível contatar quando, por exemplo, se compara a elevada proporção de espécies pioneiras e reduzida área basal do componente arbóreo de A1 e A2.

Os valores da área basal de A1 e A2 foram semelhantes ao descrito por Amador e Viana (2000), que verificaram 3,45 e 4,74 m² ha-1, em capoeiras baixas de Floresta Estacional em Piracicaba, SP. Entretanto, Melo e Durigan (2007) observaram área basal de 17,26 $\mathrm{m}^{2}$ ha $^{-1}$ em uma área de 7 anos, no Médio Vale do Paranapanema, mesma idade das áreas deste estudo.

Em contrapartida, a densidade da A1 foi maior que a de $\mathrm{A} 2$ e menor do que a de AR, sugerindo que, estruturalmente, A1 encontra-se em estágio intermediário em relação às outras duas. $\mathrm{Na} \mathrm{A} 2$, a baixa densidade está relacionada com três fatores: o maior espaçamento inicial utilizado no arranjo; a presença de camadas restritivas ao crescimento radicular, devido à presença de resíduos de construções; e a falta de manejo após o plantio, o que possibilitou a presença permanente de gramíneas invasoras, competindo com os indivíduos arbóreos e impedindo o desenvolvimento de algumas espécies nativas menos agressivas. O menor espaçamento inicial em A1, desde a implantação, proporcionou maior densidade à área, o que implicou rápida cobertura de copa em relação à A2 (Tabela 1).

Resultados semelhantes foram obtidos por Souza e Batista (2004), que, ao avaliarem áreas em restauração de 5, 9 e 10 anos, com plantios de 2.000 árvores/ha, observaram que a área foi dominada por poucas espécies pioneiras, que se desenvolveram em competição com gramíneas, levando a um baixo número desses indivíduos na regeneração.

Considerando a influência dos diferentes espaçamentos de plantio e as densidades obtidas, os valores encontrados para a cobertura de copa evidenciaram que A1 é expressivamente mais sombreada do que a A2. Essa situação possibilitou redução de gramíneas e, consequentemente, o estabelecimento de maior número de indivíduos regenerantes na A1 (Tabela 1).

Conforme Melo (2010), a cobertura vegetal controla a quantidade, qualidade e distribuição de luz, interferindo no crescimento e sobrevivência de plântulas e determinando a composição vegetal. No entanto, a cobertura de copas apresenta elevada variação em função do ambiente e da idade. Nesse sentido, Melo et al. (1995), em plantios de três anos no Estado de São Paulo, encontraram 163,47\% de cobertura de copa.

Percebe-se, dado o percentual de cobertura de copa, que a A1 apresenta maior possibilidade de atingir os objetivos de restauração. O valor da riqueza de espécies observado nas áreas em restauração foi inferior ao verificado na AR, fato que se repetiu quanto ao componente arbóreo e à regeneração (Tabela 1). A princípio, observou-se que algumas espécies, como Schinus terebinthifolius e Inga vera, plantadas na A1, regeneram-se no local.

$\mathrm{Na}$ A2, observa-se o mesmo comportamento, em relação a Calliandra brevipes, presente no estrato arbóreo. No entanto, a A2 apresentou menor riqueza de espécies na regeneração, em virtude do substrato de crescimento das plantas e da reduzida cobertura das espécies plantadas (cerca de 36\% da área), caracterizando um ambiente desfavorável. De forma comparativa, Chada et al. (2004), em área de encosta reflorestada com leguminosas com 7 anos de idade, encontraram maior riqueza (50 espécies) na regeneração natural. 
A diversidade observada no estrato arbóreo da A1 é menor em comparação com a verificada em A2 e AR, as quais apresentam valores mais próximos (Tabela1). Entretanto, a área de referência (AR), por representar floresta secundária em estágio médio a avançado de sucessão, pode, ainda, apresentar predomínio de algumas espécies, assemelhando-se ao índice de diversidade de uma área implantada. $\mathrm{Na}$ regeneração natural, a riqueza florística da AR foi suficiente para permitir o desenvolvimento de várias espécies, possibilitando um índice de diversidade superior em relação às áreas em recuperação em razão, possivelmente, do maior sombreamento e fluxo de diásporos (Tabela 1).

Comparando a outras pesquisas realizadas em plantios de restauração, Melo e Durigan (2007) encontraram valor inferior $\left(\mathrm{H}^{\prime}=2,28\right)$ aos obtidos neste estudo, na área de mesma idade. Em outros estudos, Colmanetti et al. (2011) constataram H'= 3,84 e J' = 0,62, devido ao maior número de espécies utilizadas.

Na regeneração, Nóbrega et al. (2008) observaram em áreas com 13 anos de restauração, no Estado de São Paulo, maior valor de diversidade $\left(H^{\prime}=2,4\right)$ e valores similares para Pielou $\left(\mathrm{J}^{\prime}=0,8\right)$, comparados à A1 e A2. Entretanto, ressalta-se que tais diferenças em relação aos resultados desse estudo, em ambos os estratos, podem ser atribuídas a outros fatores, como distância da fonte de propágulo, número de espécies utilizadas e sua funcionalidade, arranjo, qualidade do solo, entre outros.

Na A1, o grande número de indivíduos e dominância absoluta de Ateleia glazioviana (timbó) contribui com adição de nitrogênio no solo, demonstrando o aspecto funcional da espécie no ambiente. Essa resposta pode ser respaldada por Baggio et al. (2002), que encontraram elevada concentração de $\mathrm{N}$ na matéria seca dessa espécie (3,12\% em folhas e ramos finos). O Enterolobium contortisiliquum foi a espécie mais representativa, utilizada no plantio da A2 devido, provavelmente, à sua rusticidade e funcionalidade, visto que é uma planta capaz de desenvolver em solos pobres, como os que ocorrem na área, e tolerar a toxidade de metais pesados quando presentes (SILVA et al., 2011). As espécies Pinus elliottii, Ficus luschnathiana e Syzygium cumini, por serem indivíduos remanescentes na área, apresentam maiores valores de dominância.

Na regeneração das áreas A1 e A2 predominou espécies pioneiras zoocóricas, com grande capacidade de atração da avifauna, o que poderá ser favorável ao desenvolvimento da floresta. Porém, verifica-se a necessidade de manejar as áreas, por meio da erradicação dos indivíduos de espécies exóticas (Tabela 3).

Os processos ecológicos, associados à atividade enzimática no solo estão relacionados à lise da biomassa microbiana, bem como à quantidade e qualidade de serapilheria depositada no solo das áreas em restauração, pois, conforme Moreira e Silva (2004), há uma relação direta do acúmulo de serapilheira de acordo com o desenvolvimento sucessional da floresta. Conforme Carneiro et al. (2008), a ciclagem de nutrientes ocorre devido ao consumo de matéria orgânica pela biomassa microbiana, catalisada pelas enzimas, que quebram substratos orgânicos de menor peso molecular, facilitando sua mineralização.

Provavelmente, a cobertura do solo tenha influenciado na atividade enzimática, uma vez que as áreas em restauração, com dossel intermediário, apresentam gramíneas, como no caso deste estudo. Estas ocupam maior cobertura na A2 do que na A1, diferente da área de referência (floresta secundária), que dispõe de densa camada de serapilheira composta de folhas e galhos do dossel, característica típica de Floresta Estacional Subtropical.

Adicionalmente, a ordenação das parcelas e espécies com relação às enzimas, para o estrato arbóreo das áreas em restauração (A1 e A2) e da área de referência (AR) (Tabela 4), indica que as variáveis utilizadas influenciam a área basal das espécies adultas e abundância da regeneração. Isso se deve ao fato de que as enzimas urease e amidase atuam como catalisadoras no ciclo do nitrogênio, enquanto a fosfatase e a arilsulfatase atuam no ciclo do fósforo e enxofre, respectivamente, aumentando a velocidade das reações e disponibilizando o elemento mais rapidamente no solo (USHIO et al., 2010).

No estrato arbóreo da A1, na camada de $0-5 \mathrm{~cm}$ de solo foi evidente a ação da amidase e, consequentemente, com o ciclo do nitrogênio $(\mathrm{N})$, bem como com a importância da ciclagem do enxofre orgânico pela arilsulfatase, conforme descrito por Moreira e Siqueira (2006).

A urease participa do ciclo do $\mathrm{N}$, contribuindo para a liberação de $\mathrm{N}$-inorgânico a partir de compostos inorgânicos. Considerando esse resultado, alguns estudos indicam que a atividade da urease é baixa nos estágios iniciais de sucessão, aumentando com a sua 
progressão, o que é explicado pelo tipo de vegetação e matéria orgânica adicionada durante a sucessão (PANCHOLY; RICE, 1973; HAN et al., 2013).

A presença da atividade da fosfatase, na camada de 0-5 cm de profundidade do solo, na A2, embora sem expressiva serapilheira, pode ser justificada pela presença de diversas gramíneas. $\mathrm{Na}$ AR, a densa camada de serrapilheira contribui para a formação da matéria orgânica, principal fonte de nutrientes para o crescimento das plantas (MATSUOKA et al., 2003). Entretanto, há probabilidade de as duas áreas apresentarem baixos teores do elemento, pois Dick (1994) observou reduções nos níveis de atividade da fosfatase de acordo com o aumento do fósforo na solução do solo.

Dessa forma, é possível verificar que os atributos estudados estão exercendo sua função no armazenamento de nutrientes e na regulação da ciclagem da matéria orgânica, aspectos-chave para o processo de restauração de áreas alteradas.

\section{CONCLUSÃO}

a)As duas áreas em restauração estão retomando a sucessão natural, visto que diversidade, estrutura e processos ecológicos se apresentam crescente em relação à área de referência, porém, para possibilitar maior complexidade do ecossistema, as áreas devem ser manejadas para eliminação de exóticas.

b) A atividade das enzimas amidase, urease, fosfatase e arilsulfatase demonstrou ser um bom indicador de restauração ecológica, comprovando que as duas áreas restauradas retomaram o processo de sucessão, entretanto não atingiram a condição da floresta natural (área de referência).

\section{AGRADECIMENTO}

Ao CNPq, pela concessão de bolsa de produtividade em pesquisa para o segundo autor.

\section{REFERÊNCIAS}

AMADOR, D. B.; VIANA, V. M. Dinâmica de capoeiras baixas na restauração de um fragmento florestal. Scientia Forestalis, n.57, p.69-85, 2000.

APG III. An update of the Angiosperm Phylogeny Group classification for the ordens and families of flowering plants: APG II. The Linnaean Society of
London. Botanical Journal of the

Linnean Socity, v.141, n.4, p.399-436, 2009. Disponível em: <http://onlinelibrary.wiley.com/doi/ 10.1046/j.1095-8339.2003.t01-1-00158.x/full>. Acesso em: 4 out. 2011.

BAGGIO, A.; MONTOYA, L.; MASAGUER, A. Potencialidaddel timbó (Ateleia glazioviana) y el maricá (Mimosa bimucronatha) para laprodution de biomassa verde em zonas de clima subtropical. Investigação AgráriaProducción y Potencción Vegetales, v.17, n.1, p.102-112, 2002.

BROWER, J. E.; ZAR, J. H. Field and laboratory methods for general ecology. 2.ed. Iowa: Brow Publishers, 1984. 226p.

CARNEIRO, M. A. C.; SIQUEIRA, J. O.; MOREIRA, F. M. S.; SOARES, A. L. L. Carbono orgânico, nitrogênio total, biomassa e atividade microbiana do solo em duas cronossequências de reabilitação após mineração de bauxita. Revista Brasileira de Ciência do Solo, v.32, n.2, p.621-632, 2008.

CHADA, S. S.; CAMPELLO, E. F. C.; FARIA, S. M. Sucessão vegetal em uma encosta reflorestada com leguminosas arbóreas em Angra dos Reis, RJ. Revista Árvore, v.28, n.6, p.801-809, 2004.

COLMANETTI, M. A. A.; BARBOSA, L. M ; SHIRASUNA, R.T. ; ORTIZ, P.R. Caracterização florística de espécies nativas de um reflorestamento implantado com alta diversidade, há nove anos, no município de Mogi Guaçu, SP. In: SIMPÓSIO DE RESTAURAÇÃO ECOLÓGICA: Desafios atuais e futuros, 4., 2001, São Paulo. Anais... São Paulo: CERAD - Instituto de Botânica de São Paulo, 2011. p.295.

DARONCO, C.; MELO, A. C. G.; DURIGAN, G. Ecossistema em restauração versus ecossistema de referência: estudo de caso da comunidade vegetal de mata ciliar em região de Cerrado, Assis, SP, Brasil. Hoehnea, v.40, n.3, p.485-498, 2013.

DICK, R. P. Soil enzimes activies as indicators of soil quality. In: DORAN, J. W. et al. (Ed.).

Defining soil quality for sustainable environment. Madison: Soil Science Society of America, 1994. p.3-21. 
ENGEL, V. L.; PARROTTA, J. A. Definindo a restauração ecológica: tendências e perspectivas mundiais. In: KAGEYAMA, P. Y. et al. (Org.). Restauração ecológica de ecossistemas naturais. Botucatu: FEPAF, 2008. p.1-26.

FELFILI, J. M.; CARVALHO, A. F.; LIBANO, M. A.; VENTUROLI, F.; PEREIRA, S. A. B.; MACHADO, M. L. E. Análise multivariada: princípios e métodos em estudos de vegetação. In: FELFILI, J. M. et al. (Ed.). Fitossociologia no Brasil: métodos e estudos de casos. Viçosa, MG: Universidade Federal de Viçosa, 2011. v.1.

FINGER, C. A. Fundamentos de biometria florestal. Santa Maria: UFSM/CEPEF/FATEC, 1992. 269p.

HAN, X.; TSUNEKAWA, A.; TSUBO, M.; SHAO, H. Responses of plant-soil properties to increasing $\mathrm{N}$ deposition and implication for largescale eco-restoration in the semiarid grassland of the northern Loess Plateau, China. Ecological Engineering, v.60, p.1-9, 2013.

LAMB, D.; ERSKINE, P. D.; PARROTTA, J. A. Restoration of degraded tropical forest landscapes. Science, v.310, p.1628-1632, 2005.

MARCUZZO, S. B.; ARAÚJO, M. M.; LONGUI, S. J. Estrutura e relações ambientais de grupos florísticos em fragmento de Floresta Estacional Subtropical. Revista Árvore, v.37, n.2, p.275287, 2013.

MARCUZZO, S. B. Métodos e espécies potenciais à restauração de áreas degradadas no Parque Estadual Quarta Colônia, RS. 2012. 155f. Tese (Doutorado em Engenharia Florestal) - Curso de Pós-graduação em Engenharia Florestal, Universidade Federal de Santa Maria.

MATSUOKA, M.; MENDES, C. I.; LOUREIRO, F. M. Biomassa microbiana e atividade enzimática em solos sob vegetação nativa e sistemas agrícolas anuais e perenes na região de Primavera do Leste (MT). Revista Brasileira de Ciência do Solo, v.27, n.3, p.425-433, 2003.

McCUNE, B.; MEFFORD, M. J. PC-ORD: multivariate analysis of ecological data. Version 5.0. Oregon: MjM Software Design, 2006.
MELO, A. C. G. Guia para monitoramento de reflorestamentos para restauração; Projeto Mata Ciliar. São Paulo: 2010. (Circular Técnica, 1)

MELO, A. C. G.; DURIGAN, G. Evolução estrutural de reflorestamentos de restauração de mata ciliar no Médio Vale do Paranapanema. Scientia Forestalis, n.73, p.101-111, 2007.

MELO, A. C. G.; MIRANDA, L. D.; DURIGAN, G. Cobertura de copas como indicador de desenvolvimento estrutural de reflorestamentos de restauração de matas ciliares no médio vale do Paranapanema, SP, Brasil. Revista Árvore, v.31, n.2, p.321-328, 1995.

MOREIRA, P. M.; SILVA, O. A. Produção de serapilheira em área reflorestada. Revista Árvore, v.28, n.1, p.49-59, 2004.

MOREIRA, F. M. S.; SIQUEIRA, J. O. Microbiologia e bioquímica do solo. Lavras: Universidade Federal de Lavras, 2006. 626p.

NIMER, E. Clima. In: INSTITUTO BRASILEIRO DE GEOGRAFIA E ESTATÍSTICA - IBGE.

Geografia do Brasil: Região Sul. Rio de Janeiro: 1990. p.151-187.

NÓBREGA, A. M. F.; VALERI, S. V.; PAULA, R. C.; SILVA, S. A. Regeneração natural em remanescentes florestais e áreas reflorestadas da várzea do rio Mogi-Guaçu, Luis Antônio- SP.

Revista Árvore, v.32, n.5, p.909-920, 2008.

PANCHOLY, S. K.; RICE, E. Soil enzymes in relation to old field succession: amilase, celulase, invertase, dehydrogenase, and urease. Soil Science Society of America Journal, v.37, n.1, p.47-50, 1973.

PEDRON, F. A.; FINK, J. R.; DALMOLIN, R. S. D.; AZEVEDO, A. C. Morfologia dos contatos entre solo-saprolito-rocha em Neossolos derivados de arenitos da Formação Caturrita no Rio Grande do Sul. Revista Brasileira de Ciência do Solo, v.34, n.6, p.1941-1950, 2010.

PEDRON, A. P.; DALMOLIN, R. S. D. Solos da região do rebordo do Planalto Meridional no Rio Grande do Sul. In: SCHUMACHER, M. V. et al. (Org.). A Floresta Estacional

Subtropical: caracterização e ecologia no

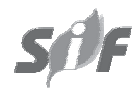

Revista Árvore, Viçosa-MG, v.38, n.6, p.961-972, 2014 
rebordo do Planalto Meridional. Santa Maria: Pallotti, 2011. 320 p.

RODRÍGUEZ-LOINAZ, G; ONAINDIA, M.; AMEZAGA, I.; MIJANGOS, I.; GARBISU, C. Relationship between vegetation diversity and soil functional diversity in native mixed-oak forests. Soil Biology \& Biochemistry, v.40, n.1, p.49-60, 2008.

RODRIGUES, R. R; LIMA, R. A. F.; GANDOLFI, S.; NAVE, A.G. On the restoration of high diversity forests: 30 years of experiences in the Brasilian Atlantic Forest. Biological Conservation, v.142, v.6, p.1242-1251, 2009.

RUIZ-JAEN, C. M.; AIDE, T. M. Restoration success: how is it being measured.

Restoration Ecology, v.13, n.3, p.569-577, 2005.

SCHUMACHER, M. V.; LONGHI, S. J.; BRUM, E. J.; KILCA, R. N. (Org.). A floresta

estacional subtropical: caracterização e ecologia no rebordo do Planalto Meridional.

Santa Maria: Pallotti, 2011. 320p.

SILVA, R. F. S.; LUPATINI, M.; ANTONIOLLI, Z. I.; LEAL, L. T.; JUNIOR, C. A. M.
Comportamento de Peltophorum dubium (SPRENG.) Taub., Parapiptadenia rigida (Benth.) Brenan e Enterolobium contorsiliquum (Vell.) Morong cultivadas em solo contaminada com cobre. Ciência Florestal, v.21, n.1, p.103110, 2011.

SOUZA, M. F.; BATISTA, F. L. J. Restoration of seasonal semideciduous forests in Brazil: influence of age and restoration desing on forest struture. Forest Ecology and

Management, v.191, n.1/3, p.185-200, 2004.

TABATABAI, M. Soil enzymes. In: WEAVER, R. W.; SCOTT, A.; BOTTOMELEY, P. J. (Ed.).

Methods of soil analysis: microbiological and biochemical properties. Madison: Soil Science Society of America, 1994. Part 2. p.778-835.

URBANSKA, K. M.; WEBB, N. R.; EDWARDS, P. J. Why restoration? In: URBANSKA, K. M.; WEBB, N. R.; EDWARDS, P. J. (Ed.).

Restoration ecology and sustainable development. Cambridge: University Press, 1997. p.3-7.

USHIO, M.; KITAYAMA, K.; BALSER, C. T. Tree species effects on soil enzime activities through effects on soil physicochemical and microbial properties in a tropical montane forest on $\mathrm{Mt}$. Kinabalu, Borneo. Pedobiologia, v.53, p.227233, 2010. 